\title{
The Indian Star Tortoise, Geochelone elegans (Schoepff 1795) (Testudinidae), a New Introduced Species in Florida
}

\author{
Michiko A. Squires, Michael R. Rochford, and Frank J. Mazzotti
}

University of Florida, Fort Lauderdale Research and Education Center, 3205 College Avenue, Fort Lauderdale, Florida 33314, USA (miker@ufl.edu)

\author{
Photographs by the senior author.
}

$\mathrm{T}$ The Indian Star Tortoise, Geochelone elegans (Schoepff 1795), is indigenous to southwestern India and Sri Lanka (Gaur et al. 2005). In its native range this species occupies agricultural fields, scrubland, and forests dominated by Acacia arabica (Vyas and Parasharya 1999).

At 1310 h on 6 August 2017, MAS collected an adult G. elegans (UF-Herpetology 180361) on a residential driveway beneath a vehicle in Kendall, Miami-Dade County (25.684284 $\mathrm{N},-80.373276^{\circ} \mathrm{W}$, Datum WGS84; Fig. 1). This species is common in the pet trade (Vyas and Parasharya 1999). This individual likely was a released or escaped pet and represents a stage- 2 introduction following Colautti and MacIsaac (2004). UF-Herpetology 180361 represents the first $G$. elegans introduced to Florida and adds to the growing number of introduced species of herpetofauna documented in the state, now totaling over 180 (Krysko et al. 2016).

\section{Acknowledgments}

We thank Dr. Coleman Sheehy for species confirmation, and Morgan Cronin, Kevin Cronin, Miki Squires, and Hana Squires for alerting us to the presence of this tortoise.

\section{Literature Cited}

Colautti, R.I. and H.J. MacIsaac. 2004. A neutral terminology to define 'invasive' species. Diversity and Distributions 10: 135-141.

Gaur, A., A. Reddy, S. Annapoorni, B. Satyarebala, and S. Shivaji. 2005. The origin of Indian Star Tortoises (Geochelone elegans) based on nuclear and mitochondrial DNA analysis: A story of rescue and repatriation. Conservation Genetics 7: 231-240.

Krysko, K.L., L.A. Somma, D.C. Smith, C.R. Gillette, D. Cueva, J.A. Wasilewski, K.A. Enge, S.A. Johnson, T.S. Campbell, J.R. Edwards, M.R. Rochford, R.T. Thompkins, J.L. Fobb, S. Mullin, C.J. Lechowicz, D. Hazelton, and A. Warren. 2016. New verified nonindigenous amphibians and reptiles in Florida through 2015, with a summary of over 152 years of introductions. Reptiles \& Amphibians 23: 110-143.

Vyas, R. and B.M. Parasharya. 1999. Distribution and status of the star tortoise (Geochelone elegans) in Gujarat State, India. Zoos' Print Journal 15: 239-242.
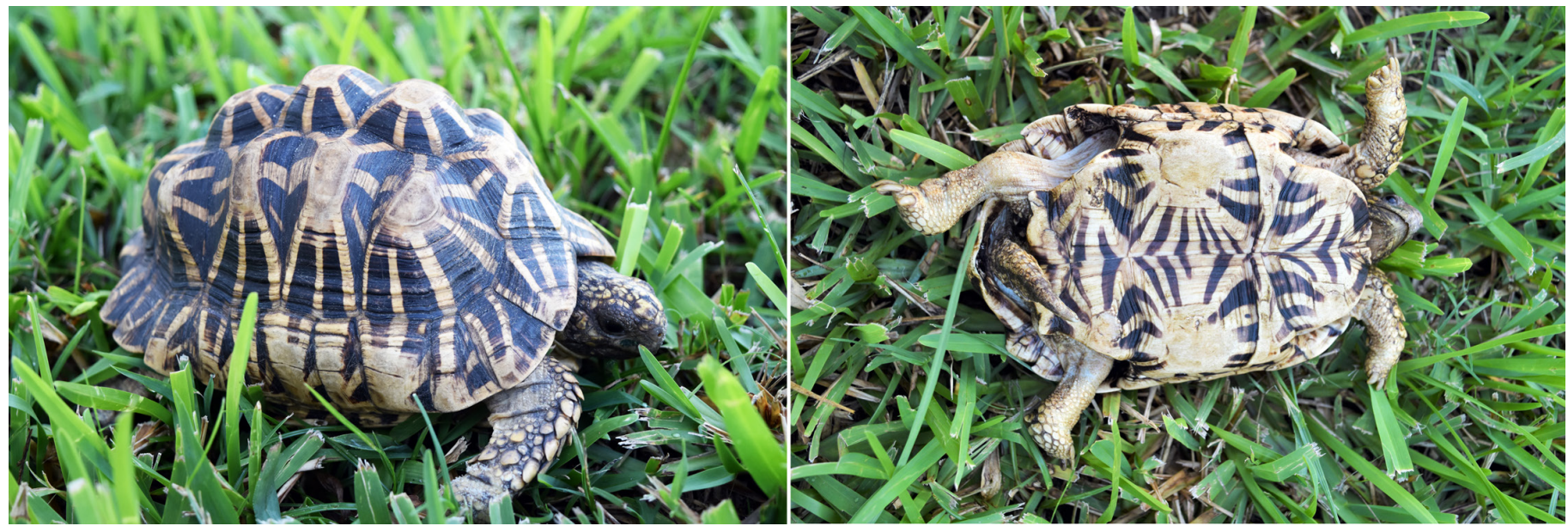

Fig. 1. Lateral and ventral views of an adult Indian Star Tortoise, Geochelone elegans (UF-Herpetology 180361), from Kendall, Miami-Dade County, Florida. 